Volume 2 Nomor. 2, Oktober 2017

P -ISSN : 2541-1179, E-ISSN : 2581-1711

OJS :http://journal.uin-alauddin.ac.id/index.php/instek/index

\title{
SISTEM PENGISIAN VOUCHER LISTRIK JARAK JAUH VIA SMS BERBASIS MIKROKONTROLLER
}

\author{
A.Muhammad Syafar \\ Dosen Jurusan Teknik Informatika \\ Fakultas Sains \& Teknologi UIN Alauddin Makassar \\ E-mail : andimuhammadsyafar@gmail.com
}

\begin{abstract}
ABSTRAK
Penelitian ini menitikberatkan pada Sistem kWH digital (prabayar) dengan fungsi pengontrol jarak jauh via sms. Tujuan dari penelitian ini adalah merancang suatu alat dalam sistem pengisian voucher listrik jarak jauh via sms berbasis mikrokonroller pada Kwh digital. Sistem pengisian voucher listrik jarak jauh ini adalah sistem yang dirancang untuk mempermudah pengisian voucer listrik dimanapun dan kapanpun.Sistem ini dibangun menggunakan SIM 800 untuk menerima sms berupa kode voucer listrik. Servo dan stepper di gunakan untuk menekan angka digit voucher pada kWH meter digital. Mikrokontroller yang digunakan adalah Ardiuno Uno sebagai kontrol utama sistem. Metode penelitian yang digunakan adalah penelitian kuantitatif. Penelitian kuantitatif yang dilakukan adalah metode penelitian eksperimental. Penelitian ini menggunakan metode pengumpulan data observasi, studi literatur, dan wawancara. Teknik pengujian yang digunakan adalah Black Box. Hasil penelitian ini adalah sebuah alat yang dapat mengisi voucher listrik jarak jauh menggunakan sms.
\end{abstract}

Kata kunci:KWH Digital,SMS, SIM800, Servo,Stepper, dan Ardiuno Uno

\section{I.PENDAHULUAN}

Di zaman moderen ini terutama di negara Indonesia energi listrik di kelola oleh PT.PLN (Perusahaan Listrik Negara ) untuk menyalurkan listrik ke rumah warga. Penyaluran listrik awalnya menggunakan metode pasca-bayar yaitu seseorang menggunakan listrik dalam sebulan setelah itu baru melakukan transaksi pembayaran tagihan listrik. Metode ini mempunyai kekurangan yaitu tagihan listrik yang di bayar setiap bulannya tidak sama, akhirnya PT.PLN mengubah menjadi metode pra-bayar. Metode pra-bayar di bagi 2 yaitu kwh meter analog, dan kwh meter digital. Seiring perkembangan teknologi saat ini masyarakat lebih banyak menggunakan kwh meter digital. 
Volume 2 Nomor. 2, Oktober 2017

P-ISSN : 2541-1179, E-ISSN : 2581-1711

OJS :http://journal.uin-alauddin.ac.id/index.php/instek/index

Salah satu kelemahan metode pasca-bayar yang akan diatasi oleh meteran listrik metode prabayar adalah kesulitan dalam pencatatan konsumsi energi listrik yang membutuhkan usaha yang lebih seperti jumlah pekerja pencatat meteran listrik, transportasi dan waktu. Dengan kondisi ini maka fluktuasi tagihan listrik kadang tidak bisa diprediksi oleh pelanggan. Khususnya di daerah terpencil, karena rumah pelanggan relatif jauh dari kantor petugas sehingga petugas pembaca meter tidak disiplin dalam melakukan perkiraan. Akibatnya tagihan pelanggan dimungkinkan tidak sama setiap bulan

Dengan penerapan meteran listrik digital (kWh digital) saat ini, pihak pelanggan diharuskan untuk mengatur sendiri penggunaan listriknya, baik dari sisi daya yang digunakan, biaya yang harus dikeluarkan untuk membeli pulsa (token) dan waktu yang diperlukan untuk masa penggunaan listrik. Sehingga antara pihak PLN dan pihak pelanggan tidak lagi bisa saling menyalahkan satu sama lain apabila ada kekeliruan dari penggunaan listrik. Meski demikian, meteran listrik digital yang digunakan saat ini masih memiliki kekurangan apabila ditinjau dari aspek kontrol dan perilaku pengguna listrik.

Dari permasalahan tersebut, dirancang sebuah terobosan baru dengan membuat suatu sistem pengisian voucher lisrik jarak jauh via sms. Pengisian ini lebih praktis tanpa bersentuhan dengan meteran, dan seseorang dapat mengisi voucher lisrik di mana saja tanpa berada di rumah.

\section{METODE PENELITIAN}

\section{A. Jenis Dan Lokasi Penelitian}

Dalam melakukan penelitian ini, jenis penelitian yang digunakan adalah penelitian kuantitatif dengan metode eksperimen. Adapun lokasi penelitian ini dilakukan di laboratorium mikrokontroller UIN Alauddin Makassar. 
Volume 2 Nomor. 2, Oktober 2017

P -ISSN : 2541-1179, E-ISSN : 2581-1711

OJS :http://journal.uin-alauddin.ac.id/index.php/instek/index

Email : instek@uin-alauddin.ac.id

\section{B. Instrumen Penelitian}

Adapun instrumen penelitian yang digunakan dalam penelitian yaitu:

\section{Perangkat Keras}

Perangkat keras yang digunakan untuk menguji coba terbagi menjadi beberapa bagian antara lain :
a.) Elektronika:
1) Arduino Uno
2) Motor Servo
3) Keypad dan LCD
4) GSM Sheild
5) Telephone seluler
6) Short Message Service (SMS)

b) Mekanik:

1) Fiber

2) Baut dan mur

c) Laptop dengan spesifikasi adalah processor AMD A8 yang kapasitas harddisk 500 GB dan memory RAM 4 GB

\section{Perangkat Lunak}

Adapun perangkat lunak yang digunkan dalam aplikasi ini adalah sebagai berikut :

a) Sistem Operasi, Windows 864 Bit

b) Software Arduino IDE 
Volume 2 Nomor. 2, Oktober 2017

P -ISSN : 2541-1179, E-ISSN : 2581-1711

OJS :http://journal.uin-alauddin.ac.id/index.php/instek/index Email : instek@uin-alauddin.ac.id

\section{Perancangan Sistem}

\section{Perancangan Alat Mekanik}

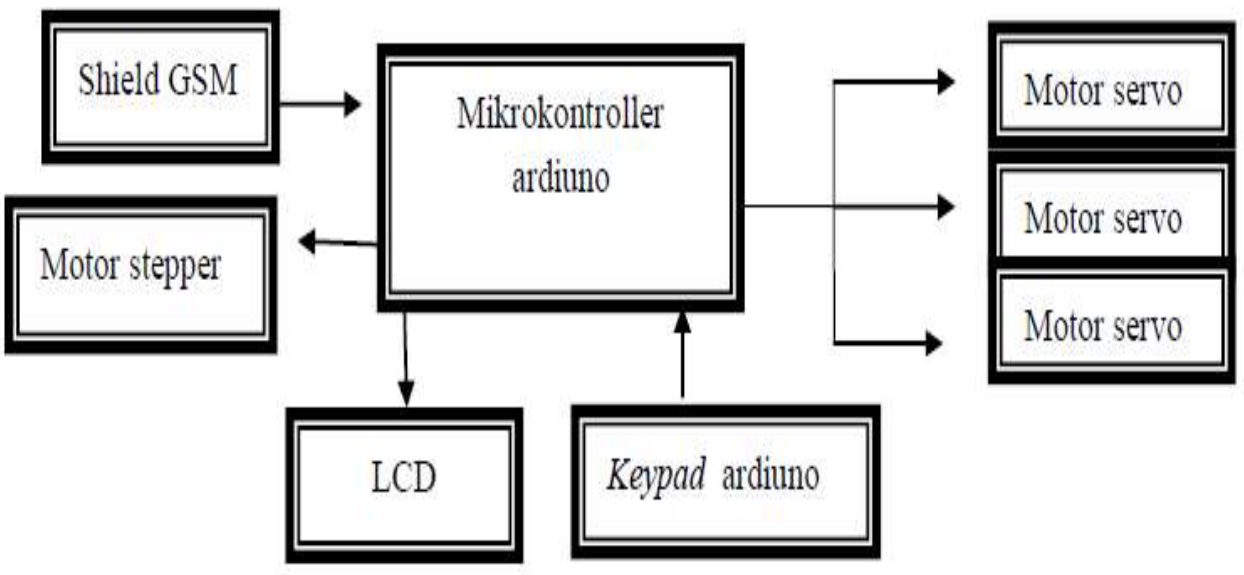

Gambar 1. Diagram Blok Sistem Alat

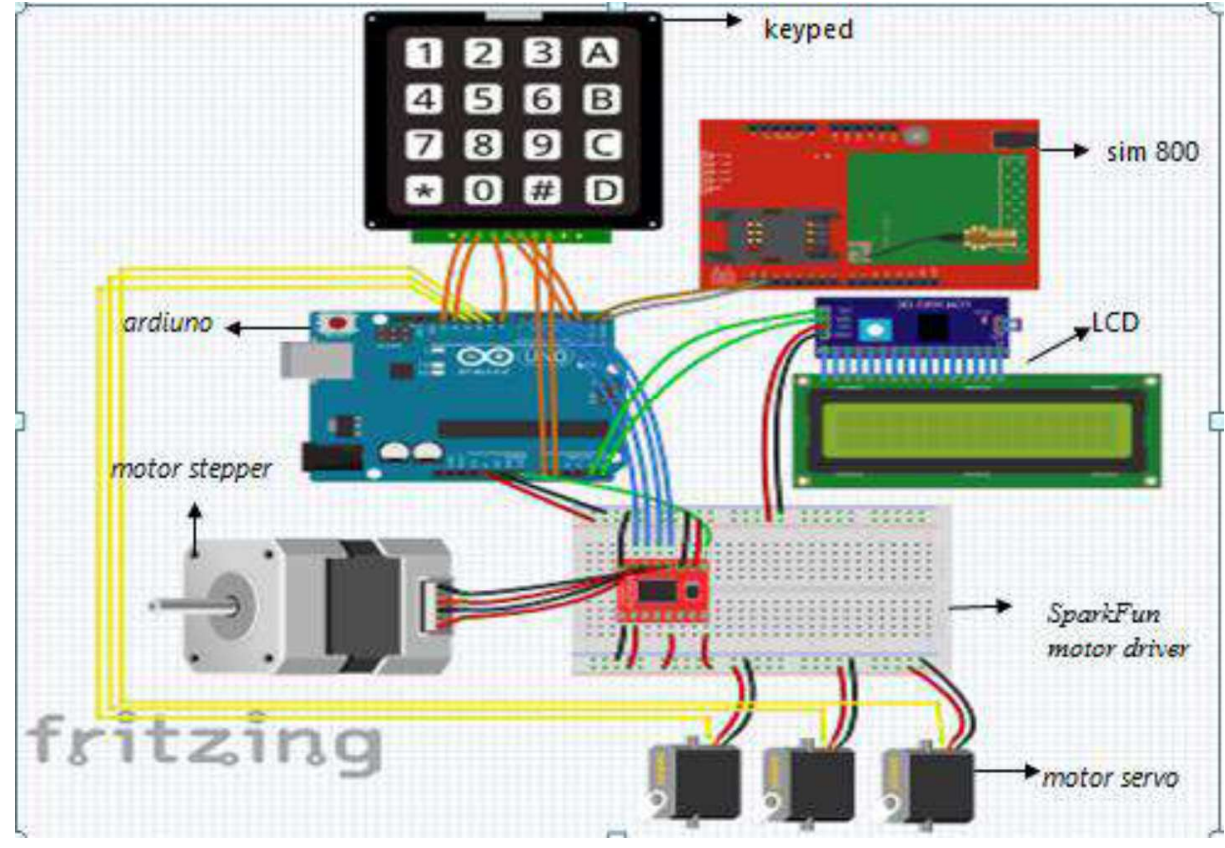

Gambar 2. Perancangan Alat Secara Keseluruhan 
Volume 2 Nomor. 2, Oktober 2017

P-ISSN : 2541-1179, E-ISSN : 2581-1711

OJS :http://journal.uin-alauddin.ac.id/index.php/instek/index

Email : instek@uin-alauddin.ac.id

\section{Perancangan Perangkat Lunak}

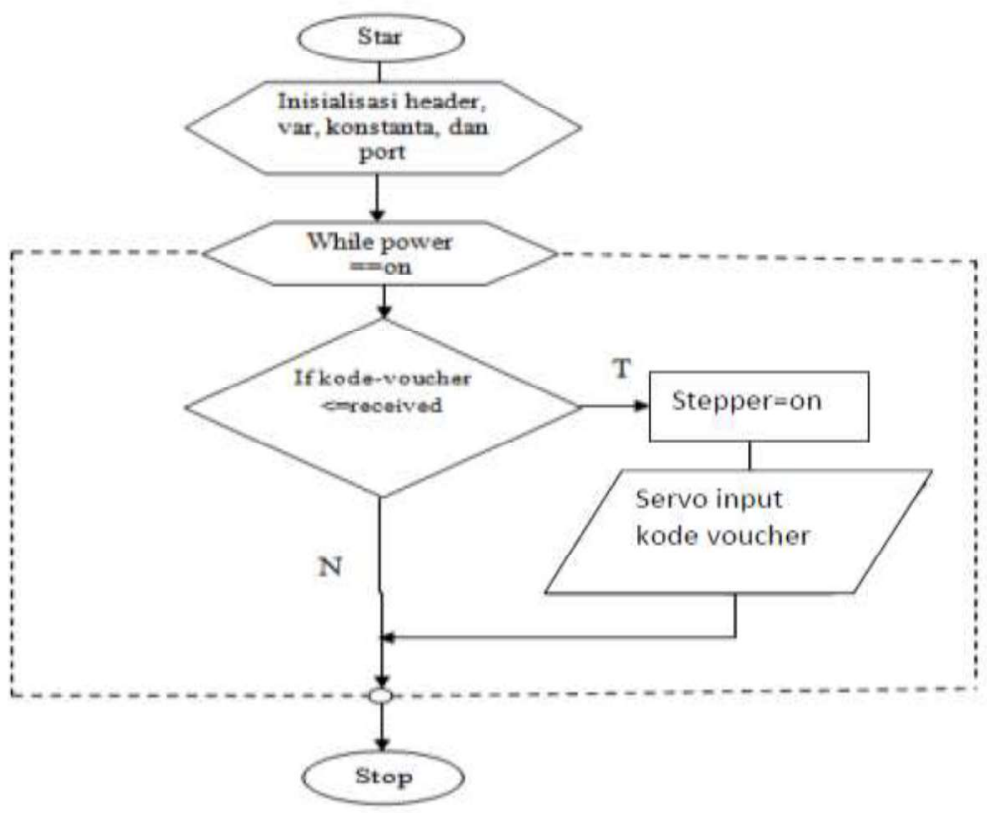

Gambar 3. Flowchart Pengisian Vouceher Listrik Jarak Jauh

\section{HASIL DAN PEMBAHASAN}

\section{A. Hasil Perancangan Perangkat Keras}

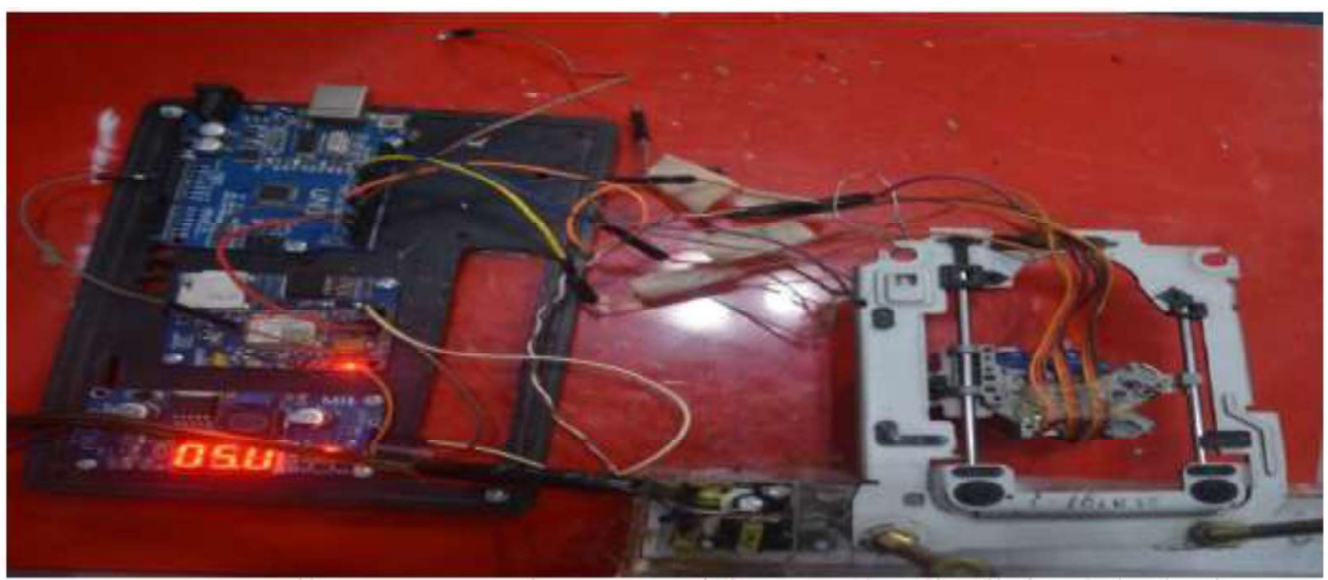

Gambar 4.Hasil Rancangan sistem pengisian voucher listrik jarak jauh via sms 
Volume 2 Nomor. 2, Oktober 2017

P-ISSN : 2541-1179, E-ISSN : 2581-1711

OJS :http://journal.uin-alauddin.ac.id/index.php/instek/index

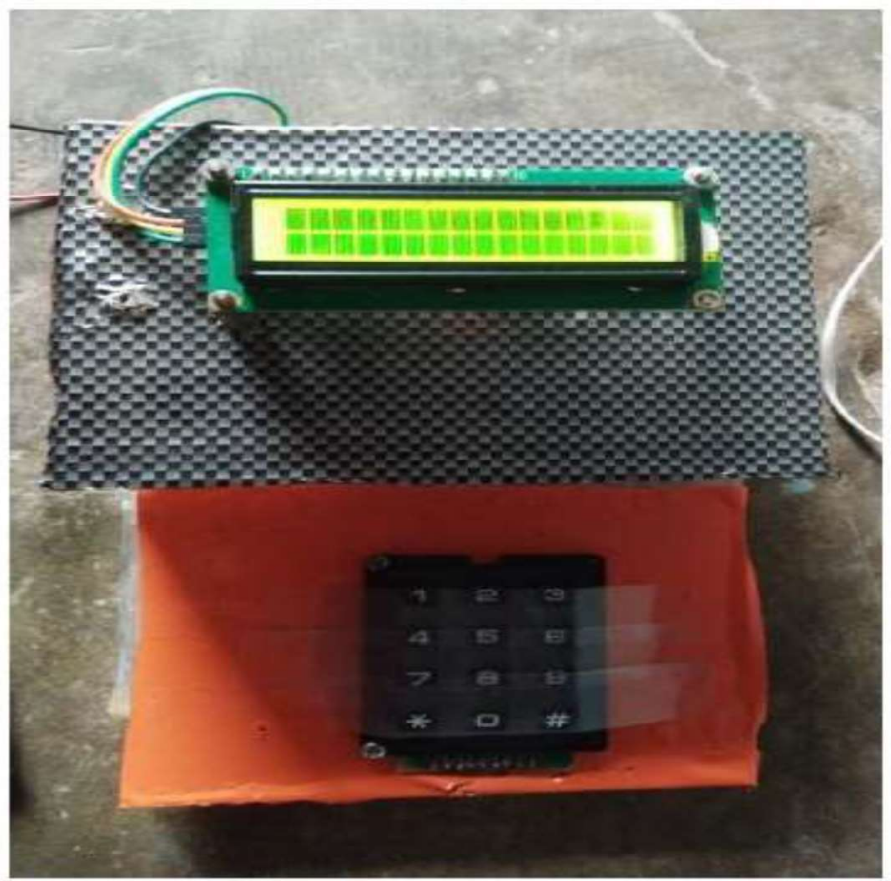

Gambar 5.keypad dan LCD yang di rakit pada kWh Meter

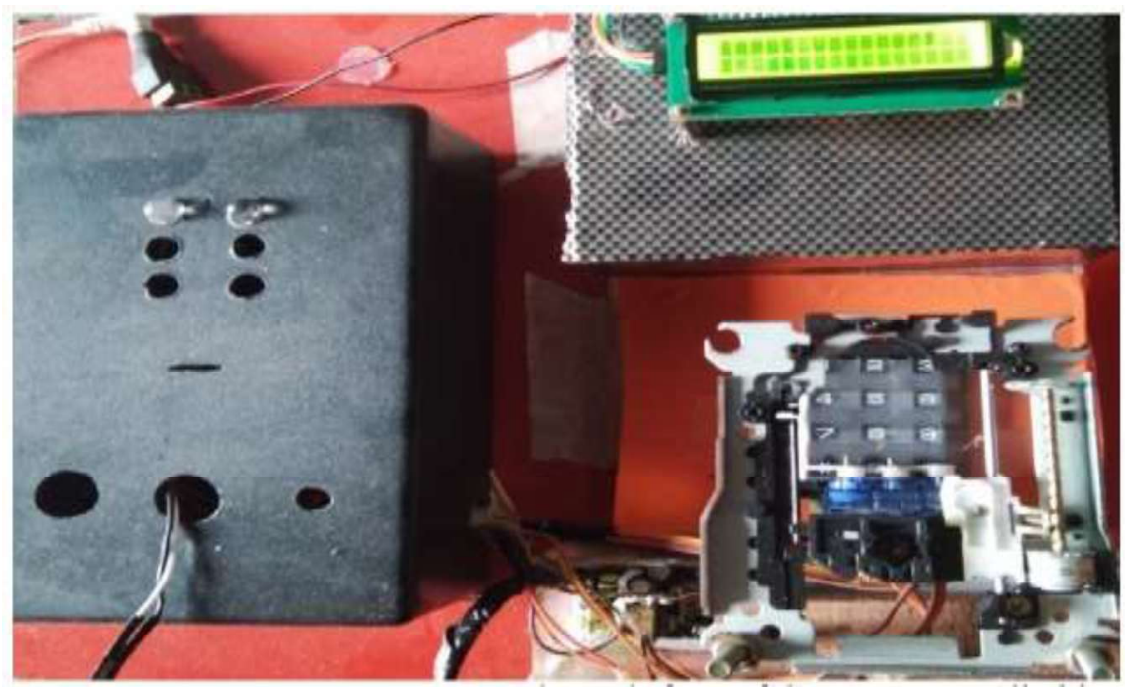

Gambar 6. pemasangan alat pada keypad dan LCD yang dirakit 


\section{B. Hasil Pengujian}

\section{Langkah Pengujian Sistem}

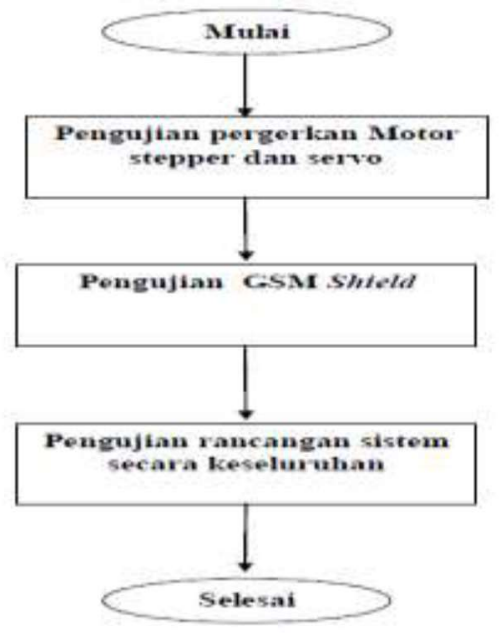

Gambar 7. Langkah Pengujian Sistem

\section{Pengujian pergerakan Motor Servo dan Stepper}

Untuk pengujian pergerakan Motor Servo dan Stepper dilakukan dengan menguji alat secara keseluruhan apakah alat mampu bergerak untuk mencapai kolom dan baris pada keypad.

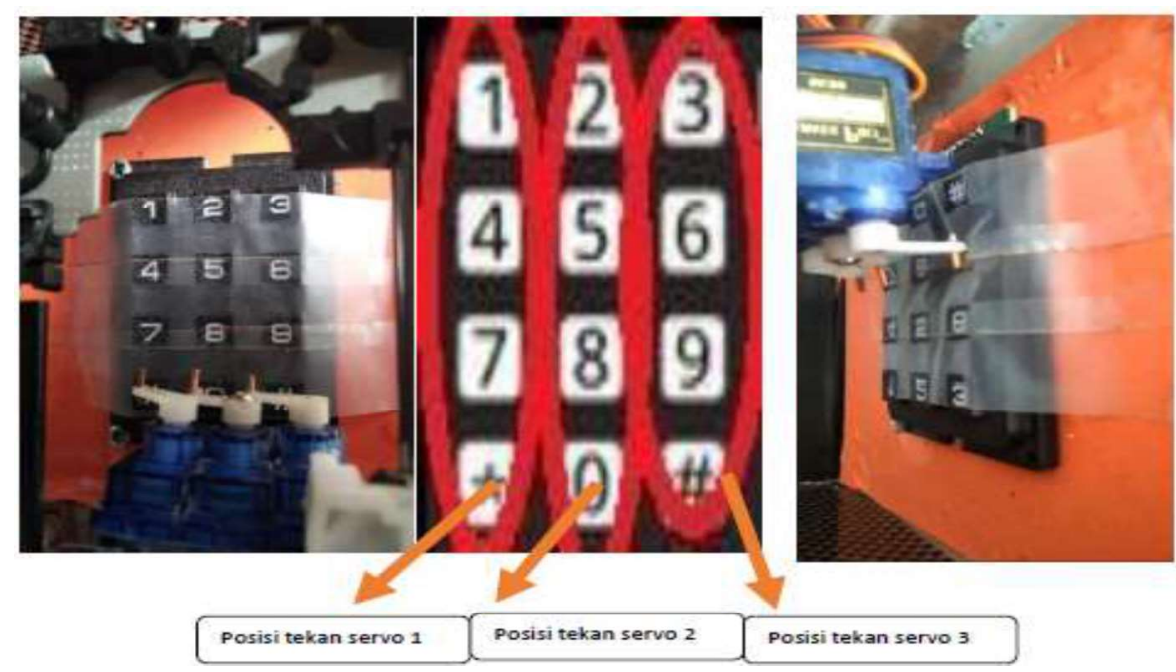

Gambar 8. Posisi Tekan Motor Servo 
Volume 2 Nomor. 2, Oktober 2017

P-ISSN : 2541-1179, E-ISSN : 2581-1711

OJS :http://journal.uin-alauddin.ac.id/index.php/instek/index

INFORIATIKASANS DAN TERNOLOGI

Email : instek@uin-alauddin.ac.id

\section{Pengujian GSM Shield}

proses inisialisasi ketika berhasil maka GSM Shield sudah aktif . Setelah GSM Shield aktif maka di lakukan pengujian dengan cara pengiriman SMS pada GSM Shield yakni mengirim beberapa angka pada GSM Shield dalam hal ini berupa kode voucher

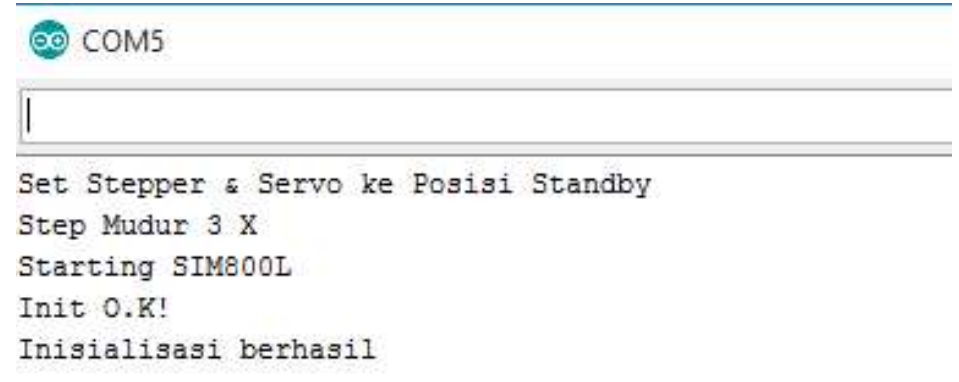

Gambar 9.GSM Shield Aktif

\section{C.Pembahasan}

Pengujian secara keseluruhan dilakukan untuk melihat proses keseluruhan pada sistem pengisian voucher listrik jarak jauh via SMS mulai dari Motor yaitu Stepper untuk bergerak ke posisi angka pada Keypad dan Servo untuk menekan angka Keypad, GSM Shield untuk mengirim beberapa angka kode voucher dengan via SMS, serta keseluruhan proses pada pengisian voucher listrik jarak jauh ini.

Ketika GSM Shield selesai menginisialisasi maka GSM Shield akan aktif dan siap untuk menerima SMS berupa kode vouher. Kode voucher akan di ubah dari Variabel Charakter menjadi integer agar dapat di Looping dan di gabungkan dengan program Servo dan Stepper

\section{Kesimpulan}

Berdasarkan hasil penelitian yang telah dilakukan didapat kesimpulan sebagai berikut :

1. Sistem pengisian voucher listrik jarak jauh via SMS berhasil di rancang dan dibuat dengan menggunakan mikrokontroler Arduino Uno dengan GSM Shield dan 2 Motor yaitu Motor Stepper dan Motor Servo. Keseluruhan sistem ini salaing 
Volume 2 Nomor. 2, Oktober 2017

P-ISSN : 2541-1179, E-ISSN : 2581-1711

OJS :http://journal.uin-alauddin.ac.id/index.php/instek/index

Email : instek@uin-alauddin.ac.id

terintegrasi sehingga apabila salah satu terganggu/error maka sistem pengisian voucher ini tidak akan berfungsi dengan baik.

2. Pengujian Motor Stepper dapat bergerak dengan 3 tahapan untuk bergerak ke keypad yang akan ditekan dapat bekerja dengan baik

3. Pengujian Motor Servo yang berfungsi untuk menekan tombol Keypad pada satu tahapan pergerakan Stepper dapat bekerja dengan baik..

\section{DAFTAR PUSTAKA}

Anung Bastiyan Nugroho Kamtomi,"Perancangan Sistem Pengisian PulsaListrik Berbasis Mobile".Jurnal Mikrokontroler Vol II, No.3 Hal. 3(2010).

Andrianto, Heri, Pemrograman Milrokontroler AVR Atmegal6 menggunakan Bahasa C (Code Vision AVR) Edisi Revisi, Bandung: Informatika.

Bishop, Owen. Dasar-dasarElektronika.Terjemahan Electronics a first course. Penerbit PT. GeloraAksaraPratama. Jakarta, 2014

Chandra M Napitupulu, "Perancangan Dan Pengendalian Kwh Meter Prabayar Berbasis Mikrokontroller Atmega8535 Melalui Telpon Seluler", Skripsi (Sumatra Utara: Fak. Matematika Dan Ilmu Pengetahuan Alam, 2011), h.29.

Heribertus Himawan, Adrin T, "Rancangan Jaringan Sistem Mobile Pulsa Listrik Prabayar". Jurnal digital, GSM, meteran,sms Vol 3, No..Hal 6-7. 2009.

Istiyanto J. E dan Efendy Y, "Rancangan Dan Implementasi Prototipe Sistem Kendali Jarak Jauh Berbasis AT89C52 Dan Layanan SMS GSM", Jurnal ILMU DASAR Vol. 5 No. 2, 2004.

JaziEko, Pengantar Elektronika Dan Instrumentasi :Pendekatan Project Arduino Dan Android, Yogyakarta: Andi, 2014.

Joseph, Alat-Alat Telekomunikasi. Edisi I: Yokyakarta: Pustaka Pelajar. 2006.

Kadir, Abdul, Panduan Praktis Mempelajari Aplikasi Mikrokontroler Dan Pemrogramannnya Menggunakan Arduino, Yogyakarta: Andi, 2013.

Katupitiya, Jayantha. Interfacipng with $C++$ Programming Real-World Applications.Berlin: Springer-Verlag 
Volume 2 Nomor. 2, Oktober 2017

P -ISSN : 2541-1179, E-ISSN : 2581-1711

OJS :http://journal.uin-alauddin.ac.id/index.php/instek/index

Email : instek@uin-alauddin.ac.id

Maulana, Iqbal. "Motor Servo Dc ". Skripsi. Bandung: Program Studi Teknik Otomasi Industri Jurusan Elektro Politeknik Negeri Bandung, 2014.

Nishino, O. Pengukuran dan Alat-alat Ukur Listrik. Cet. V. Jakarta : PT Pradnya Paramita. 2011.

Siburian, Espol. 2010. Perancangan KWH Meter Digital Dengan Sistem Prabayar Berbasis Mikrokontroler ATMega8535. Medan:USU.2010. 